\title{
Anabolic steroid accelerated multicompartment syndrome following trauma
}

\author{
H Bahia, A Platt, N B Hart, P Baguley
}

\begin{abstract}
The case is reported of a 23 year old male body builder who was involved in a road traffic accident after taking anabolic steroids. The resulting trauma caused a severe life threatening acute multicompartment syndrome resulting in the need for urgent multiple fasciotomies.

(Br F Sports Med 2000;34:308-309)
\end{abstract}

Keywords: anabolic steroids; body builder; trauma; multicompartment syndrome

Anabolic steroids such as nandrolone are used recreationally by some athletes to achieve a rapid increase in muscle bulk from the anabolic effects on muscle tissue. Chronic compartment syndrome has been described in athletes who undergo rigorous training regimes ${ }^{1}$; it may be treated by conservative methods or subcutaneous fasciotomy. Acute compartment syndrome is an emergency, presenting with severe pain in the affected limb. If surgical decompression is not performed quickly, muscle necrosis ensues accompanied by systemic metabolic effects. ${ }^{2-4}$ Delay in treatment is usually because of failure to recognise the condition, particularly in the unconscious patient with multiple injuries.

Department of Plastic

Surgery, Kingston General Hospital, Beverley Road, Hull, United Kingdom H Bahia

A Platt

N B Hart

Department of Plastic Surgery,

Middlesborough

Hospital,

Middlesborough,

United Kingdom

P Baguley

Correspondence to:

Mr H Bahia, Kingston

General Hospital, Beverley

Road, Hull HU3 1UR,

United Kingdom

email:

H.Bahia@medschool.hull.ac.uk

Accepted for publication 10 March 2000

\section{Case report}

A 23 year old man was airlifted to the casualty department of Hull Royal Infirmary after falling from his motorcycle.

All injuries were confined to the right side of the patient, and consisted of an undisplaced right radial head fracture and fractures of the right iliac crest, right femoral shaft, and a compound (Gustilo 3B) fracture of the right tibia and fibula. On the left, all muscle compartments were soft and the limbs pain-free on passive and active movement.

A full blood count on admission showed a haemoglobin concentration of $133 \mathrm{~g} / 1$ and a white cell count of $26.9 \times 10^{9} / 1$. Urea and electrolytes were normal, but the urine was dark brown and found to be very high in myoglobin and red cells. The patient was conscious throughout and at no time did he become hypovolaemic or hypotensive.

The patient was taken to theatre for right femoral and tibial nailing. The radial head and pelvic fractures were managed conservatively.

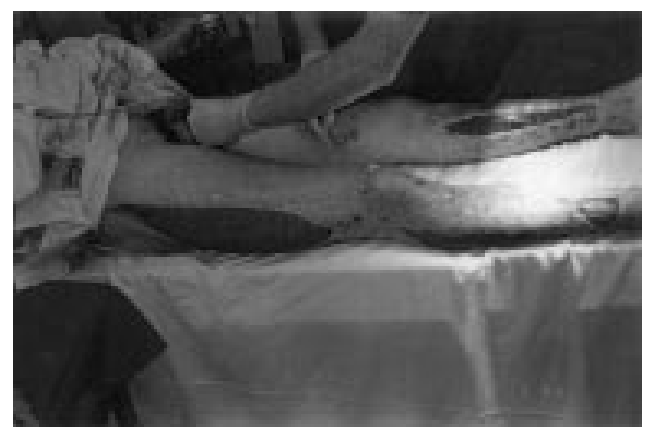

Figure 1 Right upper and lower leg and left lower leg fasciotomies. Left upper leg fasciotomy about to be performed.

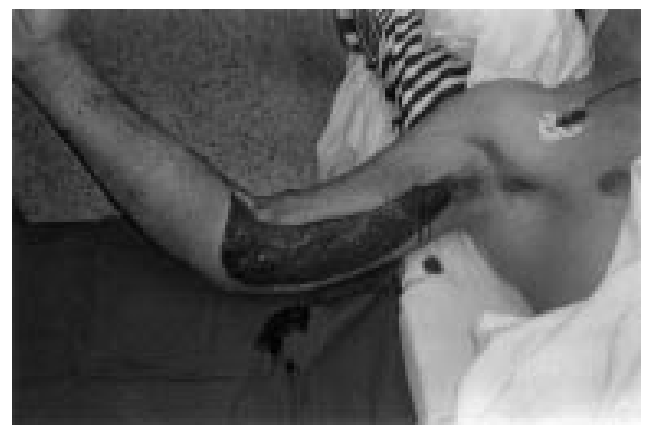

Figure 2 Right upper arm fasciotomy.

In theatre the patient's right foot was noted to be cold and dusky with absent pulses. An on table angiogram showed patent vessels proximal to the ankle, with arterial spasm, but no other vascular compromise. Fasciotomies were performed of the right thigh and all four compartments of the lower leg, which resulted in a warm pink foot.

During surgery the patient suffered an acute ventricular fibrillation/tachycardic cardiac arrest which resolved with the administration of lignocaine and calcium chloride/sodium bicarbonate The patient's potassium level, although normal on admission, had risen to $7.6 \mathrm{mmol} / \mathrm{l}$ at its peak during the arrest. He was transferred to the intensive care unit for monitoring.

Sixteen hours later he complained of severe pain and swelling in his left, uninjured, lower leg and right arm. On clinical suspicion alone of compartment syndrome, he was taken to theatre for fasciotomies of all compartments of the left lower leg and right arm (figs 1-3). The compartments were tight, with grossly ischaemic muscle which bulged through the incisions. 


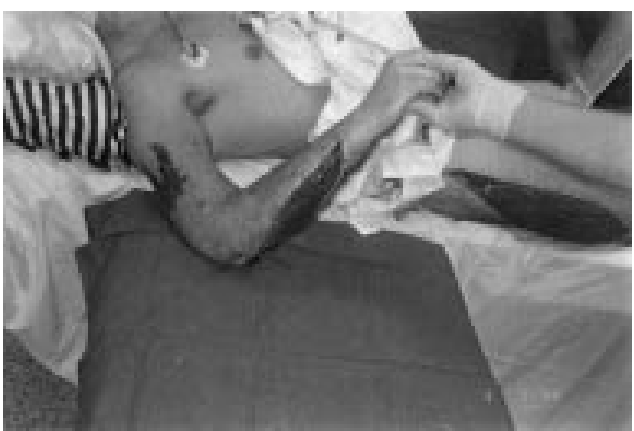

Figure 3 Right lower arm and upper leg fasciotomies.

Despite decompression, none of the muscles of the anterior compartment of the left lower leg, nor the biceps brachii improved in colour or contraction to stimulation.

The patient continued to complain of pain in both legs and right arm. Creatinine kinase levels continued to increase $(>60000 \mathrm{U} / \mathrm{l})$ and urinary myoglobin concentration remained elevated. He was therefore returned to theatre again 24 hours later. The biceps muscle of the right arm, tibialis anterior, extensor hallucis longus, and extensor digitorum of the anterior compartment of the left lower leg were all found to have patchy necrosis and required debridement, despite the complete release of the anterior compartment earlier. The right lower leg was found to have patchy superficial necrosis of the anterior compartment.

In view of the extensive and progressively worsening myonecrosis, he was transferred to the regional hyperbaric unit where he underwent twice daily treatments for three days. His condition stabilised and his wounds were later grafted.

The patient continued to make good recovery; however, one year later he is left with a fixed flexion deformity of $30^{\circ}$ of his right elbow and a left foot drop. The right leg and thigh are fully functional, but there is gross wasting of the anterior compartment muscles.

\section{Discussion}

Chronic, acute on chronic, and rarely acute compartment syndrome has been recognised in athletes ${ }^{15-8}$ and soldiers ${ }^{9}{ }^{10}$ who undergo rigorous training, which is due to an increase in volume of muscle in a tight fascial compartment, or repeated trauma. The pressure within that compartment can further increase because of compromise of the microvascular circulation which leads to an accumulation in tissue fluid both intracellularly and extracellularly. Inflammatory mediators accumulate because lymphatic and venous return are impeded producing further oedema, and a vicious cycle occurs leading to muscle necrosis. ${ }^{16}$

Anabolic steroids increase the circulating levels of low density lipoproteins, while lowering the levels of high density lipoproteins lead- ing to increased atheroma. ${ }^{4}$ They also increase coagulability leading to peripheral arterial thrombosis in athletes. ${ }^{23}$

Muscles undergoing an acute period of rapid growth as the result of exercise or the taking of anabolic steroids may be more susceptible to compartment syndrome because of the rapid expansion of the muscles in a less elastic fascial sheath.

Our patient had taken nandralone (DecaDurabolin) before the accident and was returning from a heavy exercise session when his injury occurred. Although it is common for compartment syndrome to occur in the presence of a fracture, severe contusion, or a crush injury, we postulate that the increase in muscle bulk due to the exercise along with the use of anabolic steroids brought about the severe compartment syndrome seen in this patient, affecting three of his four limbs including areas apparently not affected by the trauma.

\section{CONCLUSION}

Compartment syndrome is well recognised in athletes, most commonly in the lower leg, but may occur in any fascial compartment as the result of swelling of the muscles after intensive exercise or trauma. Although we cannot prove that anabolic steroid abuse was the direct cause of this patient's multiple compartment syndromes, we postulate that it may produce increased susceptibility to the condition because of the rapid increase in muscle volume and growth that it brings about.

Contributors: $\mathrm{H} \mathrm{B}$ is responsible for writing the bulk of the paper and performing the literature search and background reading for the purposes of the discussion. A P is responsible for writing the original draft, discussing core ideas, and correcting the paper. $\mathrm{P} \mathrm{B}$ is responsible for the original idea, developing the paper and correcting and discussing the core ideas. $\mathrm{NBH}$ is the paper and correcting and discussing the core ideas. $\mathrm{N} \mathrm{B} \mathrm{H}$ is the patient's consultant and will act as guarantor. He is also responversion of the paper.

1 Clanton TO, Solcher BW. Chronic leg pain in the athlete. Clin Sports Med 1994;13:743-59.

2 Falkenberg M, Karlsson J, Ortenwall P. Peripheral arterial Falkenberg M, Karlsson J, Ortenwall P. Peripheral arterial
thrombosis in two young men using anabolic steroids. Eur thrombosis in two young men using

3 McNutt RA, Ferenchick GS, Philip C, et al. Acute myocardial infarction in a 22-year-old world class weight lifter using anabolic steroids. Am F Cardiol 1988;62:164.

4 Hurley BF, Seals DR, Hagberg JM, et al. High-densitylipoprotein cholesterol in bodybuilders $\mathrm{v}$ powerlifters: negative effects of androgen use. $\mathcal{F} A M A$ 1984;252:507-13.

5 Kahan JSG, McClellan RT, Trigg SR, et al. Acute bilateral compartment syndrome of the thigh induced by exercise. A case report. F Bone foint Surg [Am] 1994;76:1068-71.

6 Hutchinson MR, Ireland ML. Common compartment syndromes in athletes. Treatment and rehabilitation. Sports Med 1994;17:200-8.

7 Winternitz WA Jr, Methany JA, Wear LC. Acute compartment syndrome of the thigh in sports related injuries not
associated with femoral fractures. Am $\mathcal{F}$ Sports Med 1992;20:476-7.

8 ColisimoAJ, Ireland ML. Thigh compartment syndrome in a football athlete: a case report and review of the literature. Med Sci Sports Exerc 1992;24:958-63.

9 McHale KM, Prahinski JR. Acute exertional compartment syndrome occurring after performance of the army physical fitness test. Orthopaedic Review 1994;23:749-53.

10 Blasier D, Barry RJ, Weaver T. Forced march induced peroneal compartment syndrome. A report of two cases. Clin Orthop 1992;284:189-92.

Take home message

Be aware of the possibility of multiple compartment syndromes in the muscular athlete, who may be taking anabolic steroids, who presents after trauma. 